\title{
ELF: Its Development, Problems Associated with and Suggestions for Improving Teaching Methodologies in China
}

\author{
Xiaoxia Lu \\ Xian University, China \\ 1260728600@qq.coml
}

Keywords: ELF; Problems; Implications; Teaching methodology

\begin{abstract}
As China develops fast, English teaching and learning also develops with it. However the new practices face some difficulties and resistance such as unwillingness to change long-held beliefs and perceptions, misunderstanding due to different cultures and disappointments from judgments of language proficiency and from using the ill-mannered teaching software and so on. Regardless of the problems it faces, ELF brings benefits to non-native speakers. Because of this, English has high demand, which has some implications in ELF teaching methodologies that must be flexible to attain success.
\end{abstract}

\section{Initial Development of English in China}

In the late 1970s, the Chinese government initiated new policies of expanding trade and openness around the world, which led to an increased popularity in learning and teaching foreign languages inside China. Then, the English language newspaper "China Daily" was established and TV station CCTV 9 also started broadcasting in English. Eventually, English became a compulsory subject to be assessed in the national university entrance examination. Early on, all of the English teachers were self-trained; however, in order to cultivate more English teachers to satisfy the increased demand, most universities in China added English courses to their curriculum. In the early stages of teaching English, the prevalent methodology was grammar-translation based. This methodology proved to be somewhat naïve mainly due to the teachers' own lack of proficiency in speaking and writing, as they themselves had only recently been educated locally within a short period of only 2 to 4 years. Obviously, the teaching of English under these conditions will produce less than optimal results, and teachers would spend too much of their classroom time speaking in their native tongue.

With the increase in the economic, political, and cultural exchange between countries, English has become a more-or-less de facto standard throughout the world. English education has become a standard part of the curriculum at many institutions of higher learning. Accordingly, new ideas and understanding about English learning and teaching have been constantly emerging and coming into being. Language practitioners and researchers have tried to understand English not just linguistically but also they try to explore it from a functional angel. Gradually, English has become no longer the exclusive language of Britain and the United States, but has been adopted as a common second-language around the world. From this popularity has sprung forth what we call "English as lingua franca" and is the subject of this paper.

\section{Understanding ELF}

Swan[1], differentiated ELF from EFL based on whether or not speakers communicate using Standard English. Under his definition, we can assume that English as lingua franca is independent of Standard English while English as a foreign language is generally based on Standard English. This differentiation may be too drastic and may even be partly wrong because ELF now, as House[2] pointed, is full of interlinguistic and intercultural adaptations. In principle, learners still have to follow the basic rules of Standard English. That means, linguistically speaking, non-standard English is partially derived by influence of local cultures and the first language of the speaker. This is especially true in the case of pronunciation as Jenkins[3] first found in her research. If we completely toss out the rules of English, 
then our concern is, as Seidlhofer [4]pointed out: Whose English should we follow? Do we need to coin yet a new language? On this issue, Wen [5], seemed to have provided a more flexible definition, that ELF may include aspects of the local tongue, local word order, and even include local grammar (at least to some extent). Though she seemed to show some pessimistic feeling as far as the future popularity of ELF is concerned. Actually ELF is still emerging, and its momentum is still developing and it will be some time before it reaches peak popularity. For ELF to flourish, it needs to be pushed by those responsible for setting curriculums and policy. And, it is necessary to increase and strengthen the awareness of educators.

In the learning of ELF, it is natural to make mistakes not only in the beginning but also throughout the entire course of learning. Widdowson [6]believed that learner's should be expected to make mistakes. Mistakes are a natural part of the process. Even a native speaker makes mistakes in learning his own language, let alone a non-native speaker learning a second language. Only by making mistakes can we improve our use of language and be successful. Dewey [7], described ELF as one which is often context oriented. However, his discussion about context is less than clear. My understanding of context for ELF is not one where native speakers communicate with non-native speakers, in American or British English, but one where non-native speakers from diverse cultures try to communicate with one another using a common middle language which is ELF. These ELF exchanges can be characterized as not having the participants find fault with his or her counterpart, and is equally void of harsh judgment insofar as grammar, accent, and culture are concerned. With the development of modern technology and the Internet, the world, as people often describe it, is getting smaller. We find much in the modern world that people once never even dreamed possible. In education, MOOC courses, such as those administered by Coursera, has given learners, from diverse countries, a common experience. And it is not unusual to see ELF used in online discussions and forums. Nobody is criticizing how one uses the language, so long as understandability is maintained.

\section{Problems in ELF Teaching and Learning}

Wen[5], gave an objective account of the present situation of English language learning and teaching in China, and the same is supposedly true in other Asian countries. In China, learners prefer Standard English over ELF. Although ELF seems to be increasingly accepted, changing traditional values and adopting new practices face some difficulties and resistance. It will take time to change long-held beliefs and perceptions. In Wen's description, these anticipated problems seem to be related to the non-native speaker's unwillingness to change. The Chinese researcher, Wang[8], emphasized the resistance that ELF confronts compared to mainstream English. She also sees a bright side in her study; a slightly positive attitude that some learners have towards this non-standard variety. Apart from the challenges that Wen and Wang stressed that even native-speakers of Standard English are not without their own troubling and baffling concern with their own use of the language. And, as you may guess, if native speakers of English have difficulties, what chance do non-native speakers have? Take, for example, a meeting conducted in English by a group of non-native English speaking business professionals, all of whom come from a variety of different countries, cultures and economic backgrounds. And, each participant brings his or her own form of English to the table. Now, should a native speaker suddenly arrive, they could sometimes appear as arrogant (even though they are not aware of it) and this can even spoil the tempo of the ongoing discussions and may even leads to misunderstanding. This type of misunderstanding can emerge whenever differences in accents, native tongues, cultural divides, and even social and /or economic disparities exist.

Colloquially unique ways of saying things in the Asian language can be hard to translate into English and can occasionally lead to humorous results. But, many native speakers don't seem to understand these things. The potential for non-recognition of these culturally induced difficulties by native speakers poses a challenge in ELF teaching. The very acronym ELF, already pre-supposes a difficulty because of the presumed dominance of English. The above mentioned problems do not go away simply because one is a teacher using ELF, and awareness of these difficulties should always be strived for by teachers, as well as by their students. 
The desire to be a competent English speaker may be important to non-native populations, and can lead to some disappointment as proficiency in foreign language is rarely easy. People make judgments of another person's use of language, for instance, an accent can be perceived as either bad or good. If a speaker is talking in America English to a person used to hearing British English, then it may not sound correct.

Some English teaching software, designed for non-native speakers, is really quite good but has limitations. Universities install the software on shared computers where students have access to it either as part of an English class. Or it is available for use by any student during their free time. This gives the student body an equal opportunity to access this excellent educational resource. It is designed for progressive development in the four English skills, listening, speaking writing and reading, with audio-video to provide the student with something to listen to, and student-machine interaction to help them with speaking, since it is similar to conversation in real life. This software helps improve speaking ability, especially for students who don't have alternative opportunities to talk with competent English speakers. However, the machine only recognizes a British accent or an American accent. When students want to move on to the next stage, the software sometimes won't allow them to move forward. It is not because they don't speak well, but because their accents don't match the accent programmed into the machine. Since the difficulty of this machine teaching is similar to IELTS Band 1-9, any student who can successfully follow the software to completion would gain important practice, and would find the taking of certain exams like IELTS and TOFEL to be more familiar. Reaching the last three Bands is extremely difficult. The point I want to make here is that a variety of accents shouldn't automatically be treated as incorrect, because for most non-native speakers, their second language is, to some extent, influenced by the first language, and this connection is especially obvious in speaking. The impact of software that is overly strict, leads to student frustration because students cannot move to the next stage unless they are able to get passed the current level. Skipping is not permitted, so it is annoying to do it again and again in order to satisfy the ill-mannered machine.

\section{ELF Implications in Teaching Methodologies}

It cab be said that ELF has and will continue to motivate non-native speakers because of the benefits it brings. We know that English is offered in all government schools as a compulsory subject and taught by often self-trained, non-native speakers. Due to its high demand, there are English language schools everywhere. In some cases, privileged students have parents who can afford to hire native English speaking teachers. Students, even if they are bright, may learn with difficulty if the teacher is himself not fully competent. Culturally, a native speaker should adapt the content of their lessons to the country they are teaching in as much as possible. And try to understand their student's difficulties and be flexible in methodologies. And the methodologies must be flexible to attain success. Strategies should encourage the inclusion of all types of English as long as the structure of grammar is correct. Teachers should be aware that young people have an innate ability to accept change. In fact, in Wang's 2013 study, she found her participants preferred Standard English but readily accepted alternative varieties.

It has been noticed that spoken English seems to be the weakest part for most Chinese students. For them, even after years spent studying English, in both high school and university, it is always the speaking of this foreign tongue that proves to be the weakest link. This is not the case for similar students studying English in English speaking countries. Without a doubt, the learning environment is vital for language development. The more exposure to English one gets, the better one's English will be. In non-English speaking countries, in everyday conversation, learners of English would not use that English to speak with one another. If they did, not only would they have a hard time communicating but their action would be thought of as weird. For these students, the place where they feel most comfortable using their newly acquired language skill is the internet. Many social Media are available, such as WeChat, QQ (popular for Chinese) or Pal-talk and skype, where some foreigners both native speakers (NS) and non-native speakers (NNS) offer free English speaking classes. Besides these resources, universities students themselves may form informal study groups (referred to as English corners in China) and meet either on weekends or evenings to socialize and practice their English. This 
gives them the opportunity to engage with other students or people from all walks of life and practice speaking English on any topic they are interested in and familiar with. These meetings might include foreign teachers, or foreign students, or even visitors or tourists from diverse cultures, and everybody is relaxed and free to say anything even if their English is poor or broken, and nobody will pass judgment about their proficiency but rather use the time to assist one another into acquiring improvements. These kinds of activities are usually welcomed by those who want to practice speaking English but have fewer opportunities. Activities such as English corners, very much help those who are enthusiastic about English. In this context, it is ELF that participants apply, though they may not be aware of it. Yet these English corners are only available to a relativity small portion of students. In order to improve speaking ability, there is need to reform the way language is taught. Dewey's[7][9] functionalism seems to be appropriate and should be considered for this type of educational reform. In China, the textbooks used during nine years of compulsory education should be designed with a focus on functional English. Although, text designers make efforts to design their textbooks with speaking in mind, there is always room for improvement. Jenkins[10], concluded that it is up to the teachers not the researchers to decide whether ELF to be used in the classroom, what I would argue here is that teachers have little creative control since they have to follow what is provided in the curriculum. Like researchers, teachers can only make suggestions; it is the educational policy makers that make the decisions. Current language courses do not always train students as they should. In high school, for instance, several difficulties can be sited: First, the teachers themselves are not properly trained. Second, the examination-oriented educational system, has, to some extent, restricted teachers from fully reaching their best ability. Third, there is not enough functional and cultural-oriented content included in present examinations. Currently, the verbal aspect of language takes up a relatively small percentage of time. In McNamara's[11] paper, he wrote: "Language tests have powerful positions in educational systems". If testing is designed to accept a variety of cultures then this "powerful position" will allow for a broader range of student styles (accents, cultural backgrounds, etc.) and permit the learning process to accept ELF as correct, or at least as more acceptable. If not, many otherwise bright students would end up being penalized simply because of their background. In the present system; teachers simply don't want to take the risk of alienating their superiors by deviating too far from the current way of doing things. And fourth, practice does not keep up with research. In China, at universities, some policies cause teachers to be focused too heavily on research instead of on teaching, because the academic promotion of a teacher is largely decided by a teacher's research publications, and not by their performance in teaching. If, in teaching, performance is valued equally with research and is assessed by how successful one is developing creative ways to help students, then there will be more motivation for teachers to improve their methodologies and strategies - all to the benefit of their students. At the same time, this would give teachers some impetus to balance how much time he or she spends on research and how much effort he or she gives to teaching. We know that good teaching results come from good teaching practices. If teachers are trained well and apply advanced techniques to helping their students, then great results can be achieved.

In teaching English, motivation also plays a vital role. Teachers should try to motivate their students to speak more, and should be willing to adapt to more modern ways, and not stick with the old methods that they themselves have been taught. And it should be pointed out that not all students can be taught the same way. And just like their own students, teachers also do not all learn and behave the same. Mimicking the methods of a certain educator can be both good and bad. How is a future teacher to know if the methods he or she is studying are truly effective? Teachers can improve their teaching skills by reading up-to date publications as well as by attending advanced classes and, of course, discussions with other teachers. Most importantly, teachers must understand their students' needs; they should be able to sense when a student is confused and when the student is ready to move on to more advanced lessons. In trying to motivate their students, teachers should try to find creative topics which can arouse student interest and enthusiasm. Offering encouragement is definitely a good way to motivate students. And motivated student will work harder and show more interest in their studies. Students may acquire the desire to make their teachers proud of them and this form of motivation may be amongst the best.

ELF leaning and teaching is not just limited to academic studies abroad, since not everyone can go to a university overseas. English is increasingly found everywhere, from business to tourism, and in schools. 
And these school curriculums should offer a variety of levels to cater to: General English, Academic English, or Business English and even English for Special Purposes. This would give students a choice according to the individual career orientation. ELF learning and teaching should consider career needs and demands rather than a one- size- fit- all plan.

Also, investment in teacher training is necessary and vital. Currently, qualified English teachers work mainly in big cities and well-developed areas, and only the privileged children and children from the wealthiest of families can afford to attend the best and most elite schools. While in many remote, rural areas, there is a great shortage of qualified English teachers. In order to bridge this gap, to make sure that these children are not deprived of the opportunity to learn English, local schools and government must find a way to improve this condition.

Finally, I'd like to see a change in ELF teaching. ELF in non-English speaking countries should use more audio-video presentations that contain more diverse accents. People from diverse cultures can and do speak fluent, accurate English too. I'm not saying that British or American English is inappropriate, only that some variety should be offered, so students can get used to hearing a broader range and won't feel intimidated when they are finally exposed to people from different countries where English is used as a second language - such as India or Japan. Just because the language is spoken differently from British and American English does not make it wrong.

To me, the use of video is the great untapped resource, which can be used to bring the world's best teachers within the reach of all - be they children of the elite, or children from remote and impoverished places. I see a bright future ahead for language study as well as education in general. Video may be the key to this brave new world.

\section{References}

[1] Swan, M., ELF and EFL: are they really different? Journal of English as a Lingua Franca Vol. 1(2012) No.2, pp.379 - 389 DOI 10.1515/jelf-2012-0025

[2] House, J, English as a Global Lingua Franca: A Threat to Multilingual Communication and Translation, Journal of Foreign Language Teaching \& Research in Basic Education, Vol.169 (2015) No.16, p. 27

[3] Seidlhofer, B., Anglophone-centric attitudes and the globalization of English, Journal of English as a Lingua Franca Vol.1 (2012) No.2, pp.393 - 407 DOI 10.1515/jelf-2012-0026

[4] Jenkins, J. The Phonology of English as an International Language, Oxford: Oxford University Press, 2000.

[5] Wen, Q. F., English as a Lingua Franca: a pedagogical perspective, Journal of English as a Lingua Franca Vol.1 (2012) No.3, pp.71 - 76 DOI 10.1515/jelf-2012-0024

[6] Widdowson, H. G., ELF and EFL: what's the difference? Comments on Michael Swan, Journal of English as a Lingua Franca Vol.2 (2013) No.1, pp.87 - 93 DOI 10.1515/jelf-2013-0009

[7] Dewey, M., Pedagogic Criticality and English as a Lingua Franca, Journal of the Spanish Association of Anglo-American Studies Vol.36 (2014) No.2, pp.11-30

[8] Wang, Y., Non-conformity to ENL norms: a perspective from Chinese English users, Journal of English as a Lingua Franca Vol.2 (2013) No.2, pp.55 - 82 DOI 10.1515/jelf-2013-0015

[9] Dewey, M., Towards a post-normative approach: learning the pedagogy of ELF, Journal of English as a Lingua Franca Vol.1 (2012) No.1, pp.41 -70 DOI 10.1515/jelf-2012-0007

[10] Jenkins, J., English as a Lingua Franca from the classroom to the classroom, English Language Teaching Journal Vol.66 (2012) No.4, pp.84-94 doi:10.1093/elt/ccs040

[11] McNamara, T., English as a lingua franca: the challenge for language testing, Journal of English as a Lingua Franca Vol.1 (2012) No.1, pp.199 - 202 DOI 10.1515/jelf-2012-0013 